\title{
A Quantitative Sustainability Assessment of Food Waste Management in the European Union
}

\author{
Albizzati, Paola Federica; Tonini, Davide; Astrup, Thomas F.
}

Published in:

Environmental Science and Technology

Link to article, DOI:

10.1021/acs.est.1c03940

Publication date:

2021

Document Version

Publisher's PDF, also known as Version of record

Link back to DTU Orbit

Citation (APA):

Albizzati, P. F., Tonini, D., \& Astrup, T. F. (2021). A Quantitative Sustainability Assessment of Food Waste Management in the European Union. Environmental Science and Technology, 55(23), 16099-16109.

https://doi.org/10.1021/acs.est.1c03940

\section{General rights}

Copyright and moral rights for the publications made accessible in the public portal are retained by the authors and/or other copyright owners and it is a condition of accessing publications that users recognise and abide by the legal requirements associated with these rights.

- Users may download and print one copy of any publication from the public portal for the purpose of private study or research.

- You may not further distribute the material or use it for any profit-making activity or commercial gain

- You may freely distribute the URL identifying the publication in the public portal 


\title{
A Quantitative Sustainability Assessment of Food Waste Management in the European Union
}

\author{
Paola Federica Albizzati,* Davide Tonini, and Thomas F. Astrup \\ Cite This: Environ. Sci. Technol. 2021, 55, 16099-16109 \\ Read Online
}

ABSTRACT: In an endeavor to make Europe carbon-neutral, and to foster a circular economy, improving food waste management has been identified by the European Union (EU) as a key factor. In this study, we consider 21 pathways, covering: (i) prevention; (ii) reuse for both human consumption and animal feed; (iii) material recycling as an input into the food and chemical industries; (iv) nutrient recycling; and (v) energy/fuel recovery. To include all types of impact, a sustainability assessment, encompassing environmental, economic, and social pillars, is performed and complemented with societal life cycle costing. The results indicate that after prevention, reuse for human consumption and animal

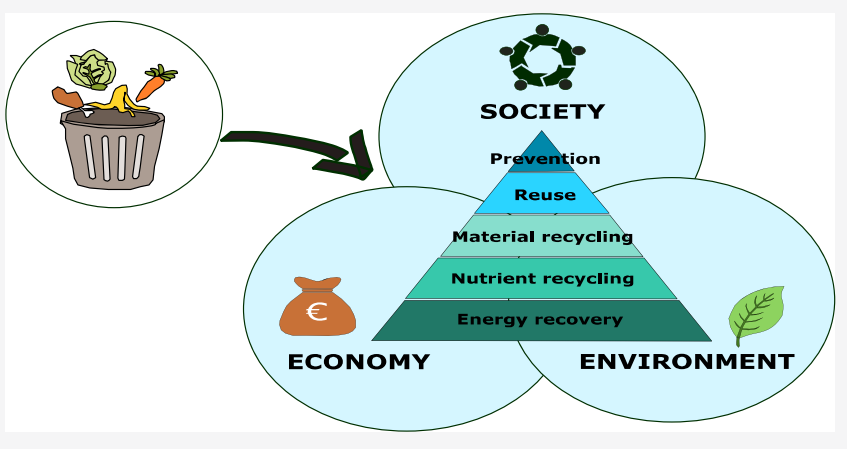
feed is the most preferred option, and, in most cases, nutrient recycling and energy recovery are favored over material recycling for chemical production. While highlighting that the food waste management hierarchy should be supported with quantitative sustainability analyses, the findings also illustrate that biochemical pathways should be improved to be competitive despite the fact that food waste valorization has the potential to satisfy the EU demand for the chemicals investigated. Yet, the results clearly show that the potential benefits of improving emerging technologies would still not eclipse the benefits related to food waste prevention and its redistribution.

KEYWORDS: LCA, societal LCC, high-value products, food waste pyramid, hierarchy, prevention

\section{INTRODUCTION}

In 2019, the European Commission launched the European Green Deal ${ }^{1}$ with the overarching goal of making Europe carbon-neutral by 2050. The Farm-to-Fork strategy, aiming at creating sustainable food systems and meeting United Nations Sustainable Development Goals, ${ }^{2}$ was a core element in the European Green Deal and looked at tackling food waste and losses across the food supply chain to achieve sustainability. ${ }^{2}$ Efforts should be expended on not only preventing food waste but also utilizing it as a resource, as supported by the food waste hierarchy. ${ }^{3}$ Both the food waste hierarchy and the bioeconomy pyramid strive in regarding food waste not as waste to be disposed of but as a resource for high-value product manufacturing. The intended effects are multifaceted. Improved utilization within the bioeconomy should contribute significant climate savings while simultaneously creating economic benefits and societal improvements. ${ }^{4}$ The consistent prioritization of initiatives, however, requires a systematic assessment of individual food waste valorization and management pathways across environmental, economic, and societal aspects.

In the European Union (EU)-27+1, about 129 Mtons of food waste was generated in 2011,5 approximately $52 \%$ of which derived from post-processing activities (i.e., wholesale and retail, food services, and households). ${ }^{5}$ Conversely, most published studies addressing the subject focus on pre-consumer food waste (i.e., production, processing, and manufacturing) primarily based on its homogeneity, thus making it particularly suitable for high-value product manufacturing. ${ }^{6,7}$ This illustrates the importance of food waste composition in terms of its quality as a feedstock and, subsequently, for the competitiveness of the conversion and valorization processes leading to marketable products. ${ }^{8}$ Viewing the entire food supply chain, households account for about $38 \%$ of all food waste, ${ }^{5}$ albeit this feedstock can vary considerably. ${ }^{9}$ Similar to households, food waste from food service activities (e.g., restaurants, catering) and from the wholesale and retail sectors, is also heterogeneous. ${ }^{9}$ The retail sector particularly represents a critical link between the production and consumption phases, potentially influencing waste generation in both stages. ${ }^{10}$ In order to improve the prioritization of initiatives potentially affecting consumers, this study clearly focuses on post-processing food waste.

The valorization of pre-consumer and post-processing food waste into different high-value products has been reviewed by

Received: June 15, 2021

Revised: September 22, 2021

Accepted: September 28, 2021

Published: November 16, 2021 
numerous studies, ${ }^{11-14}$ while others ${ }^{15-18}$ investigated and described the chemical processes involved in the conversion. Yet, performing quantitative assessments encompassing both the environmental and the economic sphere has been identified as an important aspect when evaluating the sustainability of a pathway. ${ }^{7,19}$ Most studies either assess the techno-economic feasibility $^{18,20-26}$ or perform life cycle assessments ${ }^{27-32}$ of valorization plants for, mainly, pre-consumer food waste. A few studies include cost assessments on top of the environmental one for pre-consumer ${ }^{22,33,34}$ and post-consumer ${ }^{2,34}$ food waste. However, in order to perform a sustainability assessment, all three pillars (i.e., environment, economy, and society) need to be considered. ${ }^{35}$ This clearly highlights the lack of consistent assessments across all three sustainability pillars ${ }^{19}$ for postprocessing food waste. Such assessments should reflect the importance of food waste composition and properties on the performance of individual valorization pathways, account for all co-products and side-streams, and address input data quality and uncertainties for the involved technologies. Without this systematic comparison, policymaking and regulatory initiatives may be based on qualitative expectations for environmental, economic, and societal benefits.

The study's goal is to provide consistent quantitative sustainability assessments of 21 current and emerging food waste valorization and management pathways, covering prevention, recycling, and recovery for post-processing food waste and addressing all three sustainability pillars following the method proposed in Taelman et al. ${ }^{36}$ The main novelties are the extensive coverage of pathways, impacts, and technology data as available to date. The potential of food waste valorization for meeting the European demand for selected products is evaluated, and policy recommendations for decision-makers are provided.

\section{MATERIALS AND METHODS}

Food Waste Amount and Composition. According to figures from 2011, post-processing food waste in EU-27+1 amounts to 66.3 Mtons, $10 \%$ of which is generated by wholesale and retail, $15 \%$ by food services, and $75 \%$ by households. ${ }^{5}$ An average European post-processing food waste composition was considered based on the most updated statistics, ${ }^{37,38}$ including packaging impurities, which were herein estimated at $24 \mathrm{~kg}$ per ton of food waste (Section 2 of the Supporting Information (SI)). Detailed food waste and packaging compositions are reported in Tables S1-S4 of the SI.

Sustainability Assessment. The aim of this study is to quantify the environmental, economic, and societal impacts of 21 food waste management options that mainly focus on valorization pathways for post-processing source-segregated food waste. The three sustainability pillars are quantified by means of the sustainability framework proposed in Taelman et al., ${ }^{36}$ which comprises 27 indicators for 25 impact categories at the midpoint level. These impacts at the midpoint level are expressed per functional unit, which in this study is the management of 1 ton of post-processing food waste, characterized by average European composition at the point of collection. The reference flow that satisfies the functional unit corresponds to 1.024 tons of food waste, including packaging. Note that while used as functional unit food waste, the classification of such flow (for monitoring purposes, e.g., United Nations Environment Programme ${ }^{39}$ ) may differ when sent to the redistribution/ feeding/production of biochemicals or biomaterials (i.e., food surplus United Nations Environment Programme ${ }^{39}$ ). However, in this study, the management and valorization of food waste encompass both surplus and waste for the purpose of simplicity. In most cases, indeed, the physical composition is comparable (e.g., at retails) and the difference in the classification is rather determined by the management/treatment implemented. The purpose here is to evaluate the best valorization scheme of such flow.

The 25 impact categories addressed in the sustainability framework were selected based on surveys among European stakeholders for grouping and weighting (Table S66, SI) the impact categories in five areas of protection (AoPs) at the endpoint level. ${ }^{36}$ The individual impact categories are aggregated into AoPs and weighted following a multi-criteria decision analysis (MCDA) approach (section 7.1 and excel file, SI). Two of the AoPs are environmentally centered (i.e., ecosystem health and natural resources), two are socially centered (i.e., human well-being and human health), and one is economically centered (i.e., prosperity). ${ }^{36}$ The AoP prosperity is represented by a conventional life cycle costing ${ }^{40}$ broken down into four sub-categories, namely, capital expenditure, operational expenditure, end-of-life expenditure, and revenues (Figure S23, SI) expressed as annualized unit-costs following the approach described in Martinez-Sanchez et al. ${ }^{40}$ The social impact categories considered in the AoP human well-being refer to local impacts, including urban space consumption, odor, landscape disamenities, private space consumption, total employment, and occupational health ${ }^{36}$ (remaining impact categories within such an AoP, as originally proposed in Taelman et al., ${ }^{36}$ are excluded due to lack of data) (Figure S23, SI). The AoPs human health, ecosystem health, and natural resources include the following impact categories: fossil depletion, eutrophication, ecotoxicity, land use, human toxicity, ozone depletion, tropospheric ozone formation, particulate matter, ionizing radiation, global warming, and water use (Figure S23, SI). These are quantified by means of a life cycle assessment (LCA) that is performed in concordance with the ISO standards for LCAs ${ }^{41,42}$ by adopting a bottom-up, consequential approach. ${ }^{43,44}$ The effect of indirect land use changes related to additional/prevented demand for arable land $^{45}$ and pasture land $d^{46}$ is included, and marginal market datasets are considered, ${ }^{43,44}$ representing suppliers capable of responding to changes in demand. The life cycle inventory data for background processes are based on the ecoinvent v3.6 consequential system model. ${ }^{47}$

The study is complemented by a societal life cycle costing (SLCC) that provides an aggregated picture of internal and external costs. The SLCC is performed by summing up market prices, which are equal to shadow prices under the assumption of a perfect market to external costs (i.e., externalities). In this study, the externalities of air/water/soil pollutants, ${ }^{48}$ transport (e.g., noise, accidents), ${ }^{49}$ and indirect land use changes (as the value of ecosystem losses from arable land expansion and pasture land $)^{50}$ are also accounted for. Note that a time horizon of 100 years is considered for emissions, and with respect to global warming, the uptake/release of biogenic $\mathrm{CO}_{2}$ is assigned a characterization factor equal to 0 , while a characterization factor of -1 is considered for long-term sequestration, according to common practices for short-life biomasses. ${ }^{51}$ The geographical scope of the study is the EU-27+1, while the technological and temporal scopes reflect short-term conditions (2015-2030). The assessment modeling is facilitated with the EASETECH ${ }^{52}$ software. 
Results obtained for the five AoPs of the sustainability framework, and for the SLCC, are discussed in the Results and Discussion section. Note that among the results obtained at the midpoint level, only global warming is addressed, while the other impact categories are reported in Section 6 of the SI.

Pathways. The 21 pathways are grouped into five overall "clusters", namely: (i) prevention; (ii) reuse for human consumption and animal feed; (iii) material recycling; (iv) nutrient recycling; and ( $\mathrm{v}$ ) energy and fuel recovery ${ }^{53}$ (Figure $1)$. Disposal via waste incineration without energy recovery and

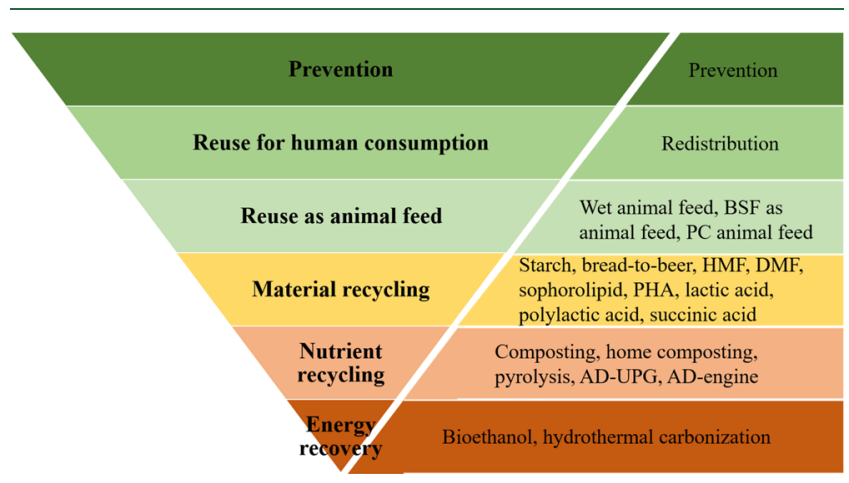

Figure 1. Overview of the pathways considered in the study together with the cluster they belong to in the food waste hierarchy. Notice that the following acronyms are used: "AD" anaerobic digestion; "BSF" black soldier fly; "DMF" dimethylfuran; "HMF" hydroxymethylfurfural; "HTC" hydrothermal carbonization; "PC" protein concentrated; "PHA" polyhydroxyalkanoate; and "UPG" upgrading.

landfilling is not considered herein, as the focus is on the valorization of source-segregated food waste. Incineration with energy recovery (SI Section 4.21) is considered for treating food waste residues and packaging, herein called "mixed residues", whereas pure organic residues are assumed to be treated through anaerobic digestion (SI Section 4.18) as these technologies are expected to increase their capacity following a consequential approach. It is notable that while the names of the scenarios generally refer to the target high-value product, additional coproducts and mixed/pure organic residues are always generated.

In the prevention cluster (encompassing the prevention pathway only), the avoided production of the totality of postprocessing food is accounted for together with its transport, corresponding packaging, and storage (SI Section 4.1).

In the reuse cluster, the redistribution pathway (i.e., reuse for human consumption) includes the redistribution of food, its transport, and storage (SI Section 4.2). It is important to note that only $68 \%^{54}$ of the food is actually redistributed; consequently, the remaining $32 \%$ is actually wasted and assumed to undergo pretreatment to remove its packaging. Outputs of the pretreatment step are mixed and pure organic residues, the former of which are transported to an incinerator plant, while the latter are transported to an anaerobic digestion plant. Outputs of the incineration process are energy (i.e., heat and electricity) and bottom and fly ashes, while products from anaerobic digestion are in the form of a digestate, which is applied on land, and biogas, which is burnt in a stationary engine to recover electricity (SI Section 4.18). With respect to reuse as animal feed, three pathways are considered: the production of wet animal feed, protein-concentrated animal feed, and black soldier fly (BSF) larvae used as animal feed. The collection and transportation of food waste to the treatment facilities, pretreatment for packaging removal, and the treatment of mixed and pure organic residues are considered as described above. The high-value product obtained from the wet animal feed production is energy feed (SI Section 4.3), that from the BSF larvae used as animal feed is protein feed (SI Section 4.4), and from the protein-concentrated animal feed production, the end products are both energy- and protein-feeds (SI Section 4.5). It is important to note that for the wet animal feed and protein-concentrated animal feeds, only products complying with the EU guidelines for animal feed production $^{55}$ were included, while the BSF larvae can be fed on any type of food residue (Sections 4.3-4.5, SI).

In the material recycling cluster, the pathways considered in the study are divided into two main groups: (i) recycling for recirculating food into the food industry and (ii) recycling for biochemical production. To the former group belong pathways focused on using bread for beer production and starch extraction, while to the latter belong hydroxymethyfurfural (HMF), dimethylfuran (DMF), sophorolipid, polyhydroxyalkanoate (PHA), lactic acid, polylactic acid (PLA), and succinic acid production. In the pathways, the collection and transportation of food waste to the treatment facilities, pretreatment for packaging removal, and the treatment of mixed/pure organic residues are accounted for as described above. In the bread-tobeer pathway, the high-value product obtained is a barleyequivalent (-eq.) substrate for beer production (SI Section 4.6), while in the starch pathway, a starch-eq. feedstock is obtained (SI Section 4.7). It is important to note that these pathways require segregating specific food waste products (e.g., for the bread-to-beer pathway only bread can be used) adding complexity to the sort and collection system. The feasibility of such collection schemes was not investigated being out of the scope of the study, but it is validated by examples of actions in place in some European cities (e.g., in Amsterdam initiatives to separately collect spent coffee grounds ${ }^{56}$ and bread ${ }^{57}$ are in place). The high-value products in the biochemical production pathways are HMF and levulinic acid in the HMF pathway (SI Section 4.8); DMF and levulinic acid in the DMF pathway (SI Section 4.9); sophorolipid and energy-feed in the sophorolipid pathway (SI Section 4.10); PHA in the PHA pathway (SI Section 4.11); lactic acid in the lactic acid pathway (SI Section 4.12); PLA in the PLA pathway (SI Section 4.13); and, finally, succinic acid in the succinic acid pathway (SI Section 4.14).

The pathways considered in the nutrient recycling cluster are composting, home composting, pyrolysis, anaerobic digestion with biogas upgrading to biomethane, and anaerobic digestion with biogas burned in a stationary engine for electricity recovery. The collection and transportation of food waste to the treatment facilities, pretreatment for packaging removal, and the treatment of mixed/pure organic residues are considered as described above. The nutrient-like products obtained in the nutrient recycling pathways are $\mathrm{N}$-, $\mathrm{K}$-, and $\mathrm{P}$-eq. fertilizers in the composting and home composting pathways (SI Sections 4.154.16); N-, K-, and P-eq. fertilizers and a peat-eq. substrate in the pyrolysis pathway (SI Section 4.17); N-, K-, and P-eq. fertilizers and biogas in the anaerobic digestion with biogas upgrading (SI Section 4.18); and N-, K-, and P-eq. fertilizers and electricity in anaerobic digestion, with biogas combustion in a stationary engine (SI Section 4.18).

The pathways considered in the energy recovery cluster are bioethanol production and hydrothermal carbonization (HTC). In these pathways, the collection and transportation of food waste to the treatment facilities, pretreatment for packaging removal, and the treatment of mixed/pure organic residues are accounted for as described above. High-value products obtained 


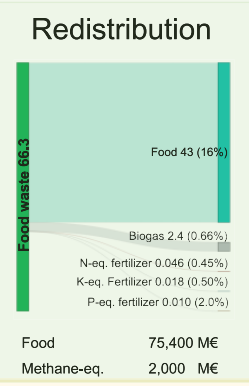

Bread to Beer

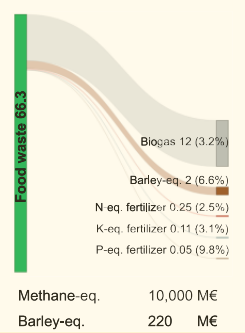

Sophorolipid

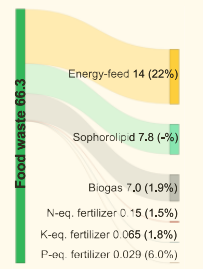

Sophorolipid $\quad 23,500 \mathrm{M} €$

Succinic acid

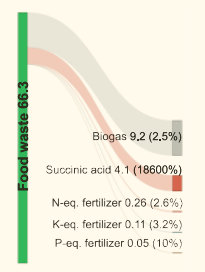

Succinic acid $\quad 17,500 \mathrm{M} €$

Methane 780 - 78

Anaerobic digestion

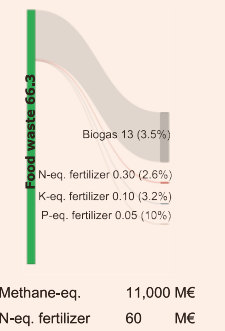

Wet animal feed

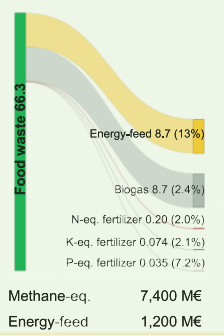

Starch

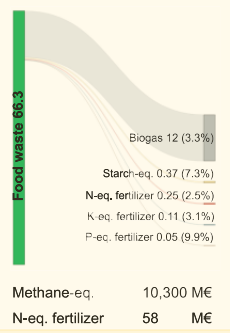

$\mathrm{PHA}$

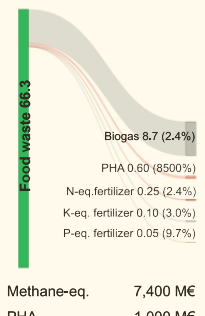

Composting

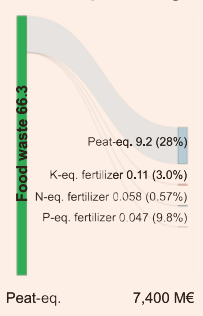

$\begin{array}{ll}\text { Peat-eq. } & 7,400 \mathrm{M} € \\ \text { P-eq fertilizer } & 31\end{array}$
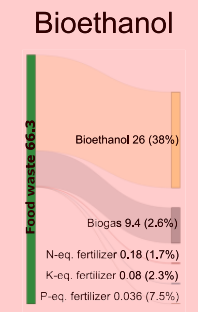

Bioethanol $\quad 20.000 \mathrm{ME}$

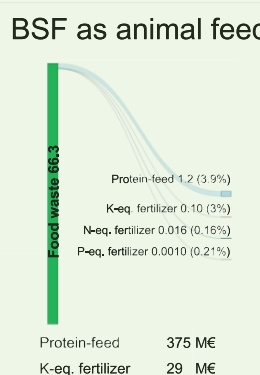

HMF

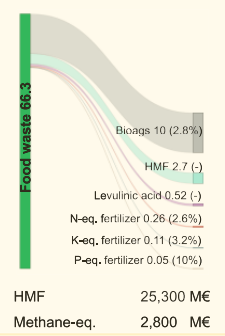

Lactic acid

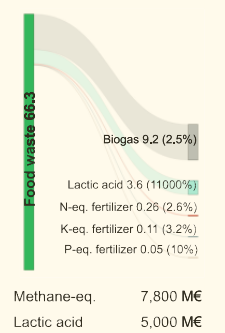

Home composting

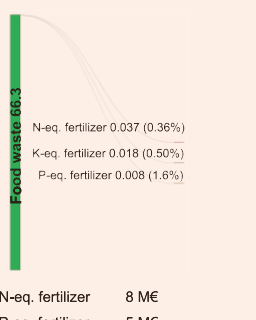

$\begin{array}{ll}\mathrm{N} \text {-eq. fertilizer } & 8 \mathrm{M} \epsilon \\ \mathrm{P} \text {-eq. fertilizer } & 5 \mathrm{M \epsilon}\end{array}$

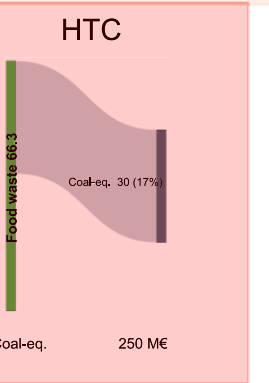

PC animal feed

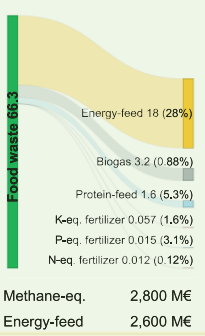

DMF

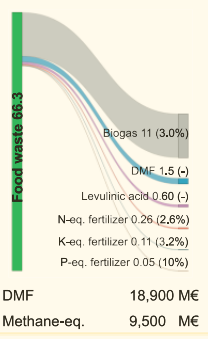

PLA

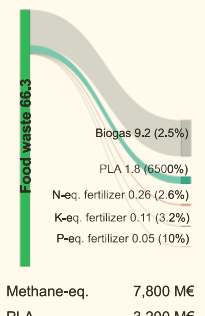

$\begin{array}{ll}\text { Methane-eq. } & 7,800 \mathrm{M} € \\ \text { PLA } & 3,200 \mathrm{M} €\end{array}$

Pyrolysis

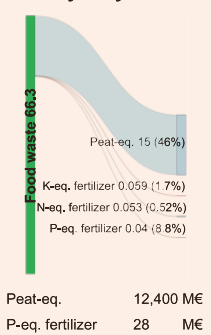

Reuse

Material recycling

Nutrient recycling

Energy recovery

Figure 2. Sankey diagrams for pathways from reuse for human consumption to energy recovery. The amounts are expressed as $\mathrm{Mtons} \mathrm{year}^{-1}$ (masses) and $\mathrm{M} €$ (revenues). The percentages reported in the parenthesis represent the share of EU-27+1 consumption for each product. Note that for each pathway, only the two products with the highest revenue are reported (M€). The following acronyms are used: "BSF" black soldier fly; "DMF" dimethylfuran; "HMF" hydroxymethylfurfural; "HTC" hydrothermal carbonization; "PC" protein-concentrated; "PHA" polyhydroxyalkanoate; and "PLA" polylactic acid.

in the pathways are bioethanol in the bioethanol pathway (SI Section 4.19) and hydrochar, used as coal substitute, in the HTC pathway (SI Section 4.20).

Details of the modeling and inventories of each pathway can be found in Section 4 of the SI. It is notable that the pure organic residues could be utilized for manufacturing other high-value products, therefore combining the different options herein analyzed. For the purpose of simplicity, we assumed them to be always digested. However, the results herein obtained can be used as basis for future optimization studies where the alternative pathways are combined to identify the optima.

System Boundaries. The study is cradle-to-grave, and the system multifunctionalities are accounted for by system expansion. $^{58}$ Waste is considered burden-free, except for 
prevention, where the system boundary is expanded upstream to account for the benefits of not producing the food that would otherwise be wasted. $^{50,59}$ The boundary includes the collection, treatment (for all residues), and transportation of the treatment residues to their final disposal sites. Any marketable co-product arising alongside the management of food waste (e.g., electricity, heat) is credited by considering the substitution of corresponding market services/products, which, following a consequential approach, are identified as marginal services/products, i.e., those capable of responding to a change in demand. ${ }^{43,44}$ In this study, it is assumed that whenever energy (i.e., electricity and heat) is produced, it substitutes the marginal energy mix, calculated based on data from the GECO2018 dataset ${ }^{60}$ (Table S39, SI). The use on land of compost/digestate is assumed to displace the marginal mineral fertilizers that are identified as the marginal mix for $\mathrm{N}$ fertilizers (urea 70.3\%, ammonium sulphate $7.3 \%$, ammonium nitrate $15.1 \%$, urea ammonium nitrate solution $7.3 \%)$, potassium chloride, and a marginal mix for $\mathrm{P}$ fertilizers (mono-ammonium phosphate $14.4 \%$, di-ammonium phosphate $76.4 \%$, single superphosphate 9.2\%) (Table S26, SI). The substitution efficiencies of NPK mineral fertilizers were 48, 100, and $100 \%$, for the digestate (Table S27, SI), 20, 100, and 100\%, respectively, for the compost (Table S19, SI), and $12 \%$ for the compost obtained from home composting (Table S22, SI). Biogas obtained from anaerobic digestion is assumed to substitute natural gas when upgraded and to displace the marginal electricity mix when burned in a stationary engine (gross electrical efficiency 24.5\%; Section 4.18, SI). With respect to animal feed, it is assumed that the energy-feed substitutes maize and the protein-feed soybean meal ${ }^{45}$ (Section 4, SI). For the remaining marginal products/services considered to be displaced in the study, please refer to Section 4 of the SI.

Sensitivity Scenarios and Uncertainty Analysis. In this study, the influence of (i) considering a low-carbon energy mix in all pathways (Section 4.23, SI) and (ii) substituting peat on top of NPK fertilizers for (centralized) composting plants are evaluated. The interpretation of the results is strengthened by means of an analytical propagation of parametrical uncertainty (Section 8, SI), ${ }^{61}$ the ranges for which are based on information retrieved from the literature. Whenever literature-based ranges were not available, a variation around the operative value of $20 \%$ is assumed for consolidated technologies (e.g., anaerobic digestion), $50 \%$ for economic-related data (e.g., price of $\mathrm{NaOH}$ ), and $100 \%$ for technologies under development (e.g., electricity consumption for lactic acid production). Furthermore, the uncertainty ranges also account for the additional uncertainty related to the parameter data quality assessment performed by means of the Pedigree matrix ${ }^{62-65}$ (SI Section 3).

Consumption Data. Consumption data for the products generated in the analyzed pathways (or current market products that are likely to be substituted) are based on the most up to date figures found for EU-27+1 (SI Section 5). Considering the totality of post-processing food waste (i.e., 66.3 Mtons per year), the annual capacity to meet the demand per product is calculated individually for each pathway. Note that EU-27+1 consumption data for HMF, DMF, levulinic acid, and sophorolipid were not available at the time of the study.

\section{RESULTS AND DISCUSSION}

Mass Balance, High-Value Products, and Annual Capacity to Meet EU-27+1 Demand. The results of the mass balance showed that in the case of PHA, lactic acid, PLA, and succinic acid, it was possible to cover current EU-27+1 demand by utilizing post-processing food waste (Figure 2). For the remaining products considered in the study, the share of the coverage of the current EU-27+1 demand varied from $0.1 \%$, for $\mathrm{N}$-eq. fertilizer in the protein-concentrated animal feed pathway, to $46 \%$, for peat-eq. in the pyrolysis pathway. For example, when applying the digestate on land, the potential capacity for the $\mathrm{N}$ eq. fertilizer to meet the annual demand varied between $0.1 \%$ (in the protein-concentrated animal feed pathway) and $2.6 \%$ (in the anaerobic digestion pathways); that for K-eq. fertilizer varied between $0.5 \%$ (in the redistribution pathway) and $3.2 \%$ (in the anaerobic digestion pathways); and, finally, that for P-eq. fertilizer varied between $2 \%$ (in the redistribution pathway) and $10 \%$ (in the anaerobic digestion pathways). When applying compost on land, the coverage of the demand for the $\mathrm{N}$-eq. fertilizer varied from $0.4 \%$ (in the home composting pathway) to $0.6 \%$ (in the centralized composting pathway); that for the K-eq. fertilizer varied from $0.5 \%$ (in the home composting pathway) to $3 \%$ (in the pyrolysis pathway); and that for P-eq. fertilizer varied from $2 \%$ (in the home composting pathway) to $10 \%$ (in the pyrolysis pathway). The coverage of the demand for maize varied between $13 \%$ (in the wet animal feed pathway) and $28 \%$ (in the protein-concentrate animal feed pathway), while for the soybean meal, it spanned from $4 \%$ (in the BSF as animal feed pathway) to $5 \%$ (in the protein-concentrated animal feed pathway). The coverage of the annual peat demand varied between $28 \%$ (in the composting pathway, when considering the sensitivity scenario) and $46 \%$ (in the pyrolysis pathway). Finally, the annual capacity of meeting the demand for methane spanned from $0.6 \%$ (in the redistribution pathway) to $3.5 \%$ (in the anaerobic digestion pathways). Note that biogas was compared to methane based on energy content.

Results obtained for the reuse cluster showed that in all pathways considered herein, the high-value products were the driving ones from a mass perspective. Indeed, if food were redistributed, it would cover $16 \%$ of the current EU-27+1 demand for food with potential revenues of 75 billion $€$, identifying food as a driving product also from an economic perspective (Figure 2). In both the wet animal feed pathway and the protein-concentrated animal feed pathway, the driving product from a mass perspective was the energy-feed substitute ( 8.7 and 18 Mtons, respectively), covering 13 and $18 \%$ of the current demand for maize, respectively (Figure 2). However, from an economic perspective, the most important product in both pathways appeared to be biogas, as the price considered in the study for energy-feed was lower than methane (145 and 850 $€ \operatorname{ton}^{-1}$, respectively). When considering the pathway of BSF used as animal feed, the most important product was the protein-feed substitute, from both a mass (1.2 Mtons) and an economic perspective (375 M€), potentially covering $3.9 \%$ of current EU-27+1 demand for soybean meal (Figure 2).

With respect to the material recovery cluster, pathways focusing on the recirculation of food in the food industry showed that the high-value products of interest were not the driving ones, from either an economic or a mass perspective (Figure 2). From a mass perspective, the biogas output was the driving product, covering $3.2 \%$ of the current EU-27+1 demand in the bread-to-beer pathway and $3.3 \%$ in the starch pathway. From an economic point of view, the biogas output incurred the highest revenues in both pathways, corresponding to 10 billion $€$ in the bread-to-beer pathway and 10.3 billion $€$ in the starch pathway (Figure 2). Indeed, the prices of barley-eq. (109€ ton ${ }^{-1}$ ) and starch-eq. (127 € ton ${ }^{-1}$ ) were lower compared to what was assumed for the biogas output. In the pathways focusing on 


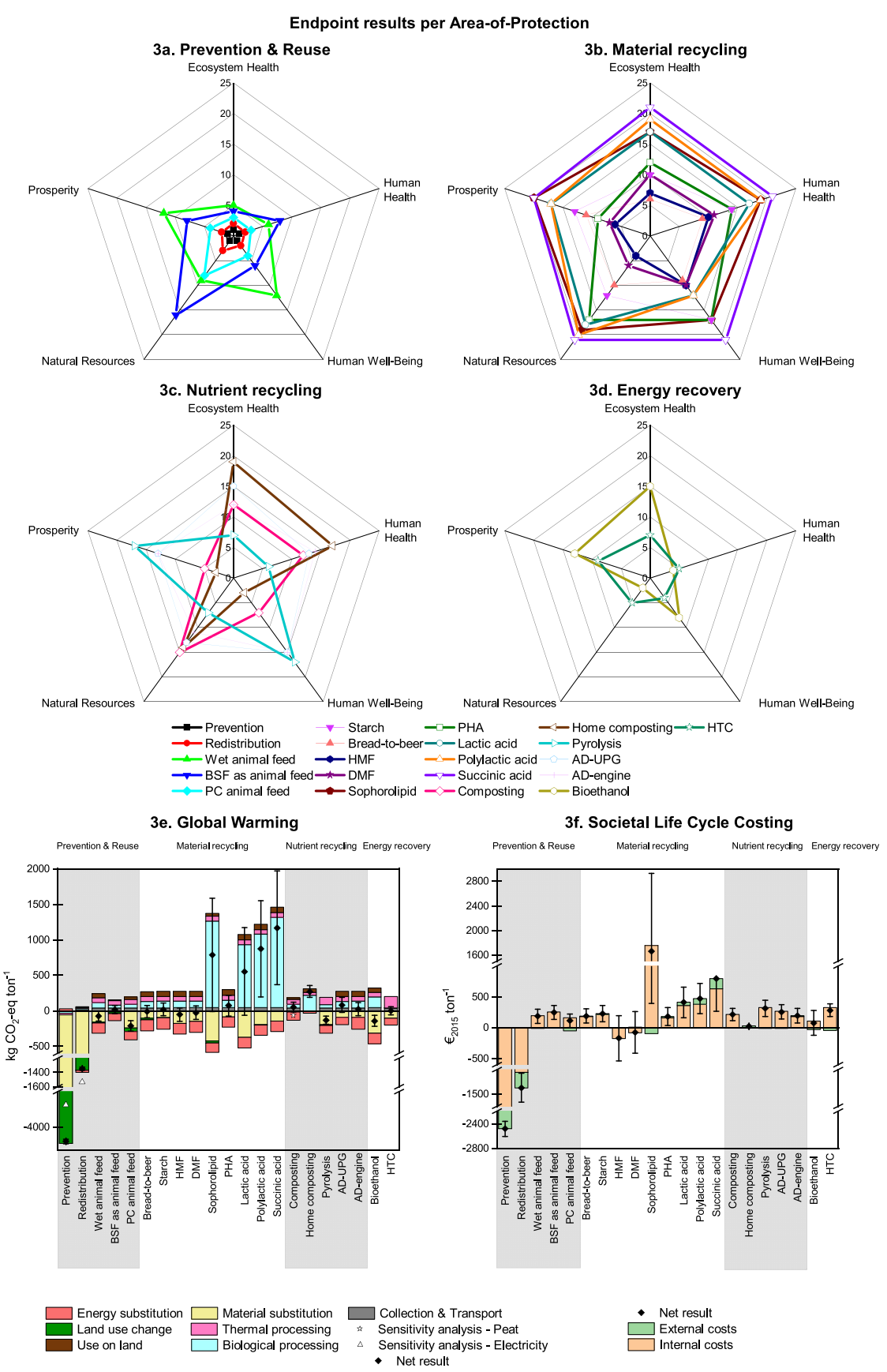

Figure 3. Results obtained for the sustainability assessment (i.e., radar graphs (a-d), where 1 is the best and 21 is the worst), global warming (e), and societal life cycle costing (f). Note that "biological processing" includes pretreatment, composting, anaerobic digestion, and fermentation processes; "thermal processing" includes the incineration of mixed residues (i.e., food waste and packaging) and treatments other than biological ones (e.g., pyrolysis); "material substitution" accounts for the substitution of all co-products generated in the scenarios other than energy; "use on land" includes emissions on land when spreading digestate/compost; "land use change" accounts for indirect land use change impacts. Note that the results are displayed with $2 \times$ standard deviations, and the results obtained for the sensitivity scenarios conducted in the study are displayed only if the results lie outside the uncertainty range around the mean result. The following acronyms are used: "AD" anaerobic digestion; "BSF" black soldier fly; "DMF" dimethylfuran; "HMF" hydroxymethylfurfural; "HTC" hydrothermal carbonization; "PC” Protein-concentrated; "PHA" polyhydroxyalkanoate; and "UPG” upgrading.

biochemical production, none of the biochemicals was the driving product from a mass perspective (Figure 2). Indeed, in the cases of HMF, DMF, PHA, lactic acid, PLA, and succinic acid, biogas was the driving product with the potential to cover $2.8,3,2.4,2.5,2.5$, and $2.5 \%$ of the corresponding current EU$27+1$ demand, respectively (Figure 2). A different trend was observed for the sophorolipid pathway, where the obtained energy-feed was identified as the driving product from a mass perspective (14 Mtons) potentially satisfying $22 \%$ of present EU-27+1 demand for maize (Figure 2). Furthermore, it was observed that the amounts of PHA, lactic acid, PLA, and succinic acid potentially obtained by utilizing the entire amount of EU$27+1$ post-processing food waste would exceed the current EU$27+1$ demand for these products $(8500,11,000,6500$, and $18,600 \%$, respectively). To satisfy the present demand for these chemicals, it would be sufficient to utilize $1 \%$ of the total 
available food waste for PHA, lactic acid, and succinic acid production, and $2 \%$ for PLA manufacture. This means that if the demand for these products increased, the EU would be able to fulfill its demand, thereby avoiding importation. However, this requires that the recycling technologies for producing these chemicals are supported and the corresponding secondary material markets are developed. The results herein provided can be used as a basis for further analyses on future waste management and valorization scenarios taking into account the development of future supply and demand for the studied products. Furthermore, from an economic perspective, in all chemical pathways except for the PHA, lactic acid, and PLA ones (as their prices were lower than the methane), the biochemical of interest was the driving product as it contributed with the highest revenue (Figure 2).

With respect to the nutrient recycling cluster, the results for home composting showed that only small quantities of agronomically available nutrients could be recovered from food waste, corresponding to 0.037 Mtons for the N-eq. fertilizer, 0.018 Mtons for the K-fertilizer, and 0.008 Mtons for P-eq. fertilizer, covering $0.36,0.50$, and $1.6 \%$ of the present EU$27+1$ demand, respectively (Figure 2). For the composting pathway, the results showed that compost would be highly beneficial when replacing peat ( 9.2 Mtons and 7.4 billion $€$ ), potentially covering $28 \%$ of the EU-27+1 demand (Figure 2 ). A similar result was observed in the pyrolysis pathway, where the peat-like product was clearly a driver from both a mass (15 Mtons) and an economic (12.4 billion $€$ ) point of view, potentially covering $46 \%$ of present demand for peat (Figure 2 ). In the anaerobic digestion pathways, biogas was the driving product, potentially providing 13 Mtons and 11 billion $€$ revenue (Figure 2).

Finally, in the pathways considered in the energy recovery cluster, high-value products were the main drivers from both a mass and an economic perspective. Bioethanol production amounted to 26 Mtons, potentially covering $26 \%$ of the present EU-27+1 demand for gasoline and corresponding to a possible revenue of 20 billion $€$ (Figure 2). Finally, the coal-eq. output could satisfy up to $17 \%$ of current demand for coal, corresponding to a $250 \mathrm{M} €$ revenue (Figure 2).

The detailed mass balance and economic results can be found in Section 5 of the SI.

Sustainability Assessment and Societal Life Cycle Costing. The aggregated results per AoP, obtained by means of the MCDA, generally support the food waste hierarchy, except for the case of material recycling into biochemicals. Prevention scored the best (i.e., 1 in the ranking in Figure $3 \mathrm{a}-\mathrm{d}$ and Table S67, SI) across all AoPs followed by reuse for human consumption, ranking second in four out of five AoPs. According to the waste hierarchy, prevention and reuse for human consumption should be followed by reuse as animal feed, material recycling, nutrient recycling, and energy recovery. However, the quantitative results herein obtained suggest that current technologies do not support this notion, particularly for biochemical production (Table S66 of the SI). Most of the biochemical pathways ranked lowest, with succinic acid manufacturing as the least preferred option. However, as already indicated by other studies, ${ }^{66,67}$ biochemical technologies are relatively recent and are characterized by low technology readiness levels (TRLs) (3-4) needing further improvements to be competitive. Based on the modeling, energy and ancillary material consumption are critical technology aspects requiring future improvements, in addition to costs for labor and capital expenditures (Section 8, SI).

Regarding the prevention \& reuse cluster (Figure 3a), the prevention of food waste generation scored the highest as the best pathway across all AoPs, incurring savings in all impact categories considered in the sustainability framework. With respect to reuse for human consumption, redistribution scored as the second-best pathway, except for AoP natural resources, as the savings obtained for fossil depletion were lower than those found in the bioethanol pathway, in which gasoline production is displaced. With respect to reuse as animal feed, the three pathways considered always scored among the top 10 across all AoPs except for the following: wet animal feed production in human well-being and prosperity, which scored 12th, and BSF as animal feed in natural resources ranked 16th. In the AoP human well-being, urban space consumption had high impacts for the wet animal feed pathway, while for BSF as animal feed, fossil resource savings were low as no methane was recovered in this pathway. The wet animal feed pathway did not score among the top 11 in the AoP prosperity, as it was observed that food collection had a high impact on operational costs and increased overall costs.

With respect to the material recycling cluster (Figure $3 \mathrm{~b}$ ), most of the pathways belonging to this group scored on the lower end, as the technologies are not optimized in terms of either energy/ancillary materials consumption or costs, both in terms of capital costs and operational costs, especially labor.

The pathways included in the nutrient recycling cluster (Figure 3c) scored similarly to those belonging to the material recycling cluster. It should be noted that home composting ranked third in regard to AoP prosperity, owing to the low costs involved.

Finally, the pathway part of the energy recovery cluster (Figure 3d) did not outperform either the material recycling or the nutrient recovery clusters, but they did have similar overall scores. As mentioned earlier, the bioethanol pathway scored second in AoP natural resources, and hydrothermal carbonization ranked fourth in AoP human well-being due to low impacts on the odor footprint and urban space consumption.

The results obtained for the SLCC (Figure 3f) showed the same trend as the MCDA. Indeed, prevention outperformed all pathways followed by reuse by redistribution, while material recycling for biochemical production, particularly for lactic acid, polylactic acid, succinic acid, and sophorolipid, had the highest societal cost. The only discrepancy with the results obtained applying the sustainability framework was observed for the ranking of the succinic acid and the sophorolipid pathways. In the sustainability assessment, the succinic acid pathway performed worst across all AoPs, while in the SLCC the sophorolipid pathway had the highest societal costs. This can be explained by the fact that in the SLCC, internal costs mostly govern the results, thus suggesting that the prices assigned to externalities are relatively low compared to their actual impacts (Figure 3f).

Global Warming. The waste hierarchy is followed with respect to the prevention cluster $\left(-4200 \mathrm{~kg} \mathrm{CO}_{2}\right.$-eq. ton $\left.^{-1}\right)$ and the reuse cluster for the pathway redistribution $\left(-1300 \mathrm{~kg} \mathrm{CO}_{2}\right.$ eq. $\left.\operatorname{ton}^{-1}\right)$ and protein-concentrated animal feed $\left(-200 \mathrm{~kg} \mathrm{CO}_{2}\right.$ eq. $\left.\operatorname{ton}^{-1}\right)$, the results for which were driven mainly by material substitution (i.e., food and energy/protein-feed) and avoided land use changes. Due to their lower material substitution, the wet animal feed $\left(-80 \mathrm{~kg} \mathrm{CO}_{2}\right.$-eq. $\left.\mathrm{ton}^{-1}\right)$ and the BSF as animal feed $\left(17 \mathrm{~kg} \mathrm{CO}_{2}\right.$-eq. ton $\left.^{-1}\right)$ pathways were outperformed by the 
pathways included in the material recycling, nutrient recycling, and energy recovery clusters.

In the material recycling cluster, the results ranged from -55 $\mathrm{kg} \mathrm{CO}$-eq. ton $^{-1}$ in the $\mathrm{HMF}$ pathway to $1200 \mathrm{~kg} \mathrm{CO}_{2}$-eq. ton $^{-1}$ in the succinic acid pathway. The DMF $\left(-30 \mathrm{~kg} \mathrm{CO}_{2}\right.$-eq. ton $\left.^{-1}\right)$ and bread-to-beer pathways $\left(-10 \mathrm{~kg} \mathrm{CO}\right.$-eq. ton $\left.^{-1}\right)$ incurred savings due to high material and energy substitution (Figure $3 \mathrm{e}$ ). The starch $\left(20 \mathrm{~kg} \mathrm{CO}_{2}\right.$-eq. ton $\left.^{-1}\right)$ and the PHA pathways $(73 \mathrm{~kg}$ $\mathrm{CO}_{2}$-eq. ton ${ }^{-1}$ ) resulted in net impacts for global warming. In the starch pathway, impacts related to the extraction of starch from food waste were higher than the avoided production of first-generation starch and the corresponding land use changes. In the PHA pathway, the production process, especially the extraction process, ${ }^{68}$ outweighed savings related to energy and material substitution (Figure 3e). Finally, lactic acid (600 kg $\mathrm{CO}_{2}$-eq. ton $\left.^{-1}\right)$, sophorolipid $\left(800 \mathrm{~kg} \mathrm{CO}_{2}\right.$-eq. ton $\left.{ }^{-1}\right)$, polylactic acid $\left(900 \mathrm{~kg} \mathrm{CO}_{2}\right.$-eq. ton $\left.{ }^{-1}\right)$, and succinic acid $\left(1200 \mathrm{~kg} \mathrm{CO}_{2}\right.$ eq. ton $^{-1}$ ) had the highest impacts on global warming, which were mainly related to the high consumption of steam and electricity in the manufacturing process, ${ }^{69,70}$ which were identified as the most important parameter in the uncertainty analysis (Table S68, SI).

The results obtained for the nutrient recycling cluster spanned from $-130 \mathrm{~kg} \mathrm{CO}$-eq. ton $^{-1}$ in the pyrolysis pathway, to $85 \mathrm{~kg}$ $\mathrm{CO}_{2}$-eq. ton ${ }^{-1}$ in the home composting pathway. Savings in the pyrolysis pathway were driven by peat substitution, which releases $\mathrm{CO}_{2}$ fossil, while impacts related to home composting were associated with direct emissions from the composting process. Anaerobic digestion with biogas combustion in a stationary engine $\left(22 \mathrm{~kg} \mathrm{CO}_{2}\right.$-eq. ton $\left.^{-1}\right)$ performed better than composting ( $50 \mathrm{~kg} \mathrm{CO}$-eq. ton $^{-1}$ ) due to the higher substitution of NPK fertilizer rates assumed in the study (Section 4 of the SI) and energy substitution. Note that in the sensitivity scenario where peat is also substituted, composting (-63 $\mathrm{kg} \mathrm{CO}_{2}$-eq. $\mathrm{FU}^{-1}$ ) would outperform not only anaerobic digestion with the burning of biogas in a stationary engine but also five of the high-value product-centered pathways (Figure $3 \mathrm{e})$. Finally, in the anaerobic digestion pathway with biogas upgrading ( $80 \mathrm{~kg} \mathrm{CO}_{2}$-eq. ton ${ }^{-1}$ ), impacts that were mainly driven by direct emissions from digestate application on land outperformed the savings that were mainly related to energy recovery (Figure 3e).

Lastly, the impacts related to the energy recovery cluster varied between $-145 \mathrm{~kg} \mathrm{CO}$-eq. ton $^{-1}$ in the bioethanol pathway and $-2 \mathrm{~kg} \mathrm{CO}_{2}$-eq. ton $^{-1}$ in the HTC pathway. In the former, the substitution of fossil-based products (i.e., gasoline) drove the savings, while in the latter, impacts related to thermal treatment were higher than the potential energy savings related to fossil coal substitution and were mainly driven by the inputspecific $\mathrm{CO}_{2}$ emissions of incinerating the mixed residues (Figure 2e).

Although observing trends similar to those obtained for the sustainability framework (Table S67, SI) and SLCC (Figure 3f), it would be misleading to base decisions only on global warming (Figure 3e), as burden shifts might occur in the other impact categories. $^{71}$ Therefore, it is important to have a holistic perspective addressing the three sustainability pillars, for example, by applying the sustainability framework.

It is notable that the complete list of results obtained for all impact categories considered in the study is provided in Section 6 of the SI.

Policy Implications. The importance and usefulness of life cycle assessment for quantifying the impacts/benefits of policies has already been recognized by the European Commission. ${ }^{72}$ However, the recommended methodology (i.e., EF3.0 ${ }^{73}$ ) focuses on products/organizations and does not quantify socio-economic system-wise impacts, which should be considered when supporting policy implementation. ${ }^{72}$ The sustainability framework applied here offers the possibility of quantifying environmental, economic, and societal impacts, and the results obtained show the importance of separately addressing the three sustainability pillars, thereby avoiding burden shifting when analyzing different policies/actions. The complementary SLCC provides an additional angle on total societal costs when environmental externalities are internalized. However, as shown by the results herein obtained, the costs of externalities are overwhelmed by internal costs, suggesting that they may not be fully representative of actual societal costs.

The current study can potentially be used to support the placement of investments by policy- and decision-makers, in order to guide the transition to a greener economy. Among the problems related to food waste valorization, the availability of feedstock, techno-economic feasibility, and the assessment of benefits/burdens on the environment by means of an LCA are critical factors. ${ }^{7}$ The results of the current study showed that emerging technologies, such as those related to biochemical or feed production (BSF as animal feed), still require process optimization to be competitive and viable from both an environmental and a socio-economic perspective. As highlighted elsewhere, ${ }^{67}$ these technologies require lower energy and ancillary material consumption, higher feedstock-to-product yield, and lower capital expenditure and labor costs to be competitive with corresponding conventional products. As the biochemical technologies considered in this study are a projection of laboratory-scale experiments, their TRL is estimated to be low (3-4). As highlighted in other studies, ${ }^{66,74}$ low TRLs lead to higher impacts (as the processes are not optimized) and they need to be considered to avoid unfair comparisons with established technologies. The results of the current study clearly support prevention followed by redistribution as the best valorization pathway for food waste, considering current technologies, across all three sustainability pillars. This holds true if rebound effects related to food waste prevention and redistribution, which were not quantified in the present study, have lower impacts compared to the benefits of avoiding food waste. Indeed, if economic savings from food waste prevention and redistribution lead to additional and more polluting consumption activities, then these pathways may not offer the expected benefits. ${ }^{50}$ This suggests that prevention and redistribution should be accompanied with other initiatives, for example, changes in consumer behavior and consumption patterns through education campaigns, to ensure their efficacy.

\section{ASSOCIATED CONTENT}

\section{SI Supporting Information}

The Supporting Information is available free of charge at https://pubs.acs.org/doi/10.1021/acs.est.1c03940.

Detailed description of the food waste composition and related packaging; implementation of the pedigree matrix and of the pathways, system boundaries and inventories used; complete set of results obtained for the covered EU demand and the multi-criteria decision analysis; complete list for all impact categories of characterized results; and the results of the uncertainty analysis (PDF) 
Multi-criteria decision analysis workbook updated from Taelman et al. $^{36}$ (XLSX)

\section{AUTHOR INFORMATION}

\section{Corresponding Author}

Paola Federica Albizzati - Department of Environmental Engineering, Technical University of Denmark, DK-2800 Kgs. Lyngby, Denmark; European Commission, Joint Research Centre, Edificio Expo, 41092 Seville, Spain; ㅈorcid.org/ 0000-0002-8679-0861; Email: paal@env.dtu.dk

\section{Authors}

Davide Tonini - European Commission, Joint Research Centre, Edificio Expo, 41092 Seville, Spain

Thomas F. Astrup - Department of Environmental Engineering, Technical University of Denmark, DK-2800 Kgs. Lyngby, Denmark

Complete contact information is available at: https: / / pubs.acs.org/10.1021/acs.est.1c03940

\section{Funding}

This study was supported by "SustEnergy" (grant no. 640170044) (Energy Technology Development and Demonstration Program, EUDP, under the Danish Energy Agency) and the REPAiR project (ID 688920) under H2020-EU.3.5.4. Enabling the transition towards a green economy and society through ecoinnovation, WASTE-6b-2015-Eco-innovative strategies.

\section{Notes}

The authors declare no competing financial interest.

The manuscript was written via contributions made by all authors. All authors have given approval to the final version of the manuscript.

The views expressed in the article are the sole responsibility of the authors and in no way represent the views of the European Commission and its services.

\section{ABBREVIATIONS}

\section{$\mathrm{AD}$ anaerobic digestion}

AoP area of protection

BSF black soldier fly

DMF dimethylfuran

EU European Union

HMF hydroxymethylfurfural

HTC hydrothermal carbonization

LCA life cycle assessment

MCDA multi-criteria decision analysis

PC protein concentrated

PHA polyhydroxyalkanoate

PLA polylactic acid

SI Supporting Information

SLCC societal life cycle costing

TRL technology readiness level

UPG upgrading

\section{REFERENCES}

(1) European Commission The European Green Deal; European Commision: 2019. https://eur-lex.europa.eu/legal-content/EN/ $\mathrm{TXT} / \mathrm{PDF} /$ ?uri=CELEX:52019DC0640\&from=EN.

(2) European Commission A Farm to Fork Strategy for a Fair, Healthy and Environmentally-Friendly Food System; European Commision: 2020.

(3) Sánchez López, J.; Patinha Caldeira, C.; De Laurentiis, V.; Sala, S.; Avraamides, M. Brief on Food Waste in the European Union; 2020.
(4) European Commission Communication from the Commission to the European Parliament, the Council, the European Economic and Social Committee and the Committee of the Regions; Bruesels: 2015.

(5) Caldeira, C.; De Laurentiis, V.; Corrado, S.; van Holsteijn, F.; Sala, S. Quantification of Food Waste per Product Group along the Food Supply Chain in the European Union: A Mass Flow Analysis. Resour., Conserv. Recycl. 2019, 149, 479-488.

(6) Cristóbal, J.; Caldeira, C.; Corrado, S.; Sala, S. Techno-Economic and Profitability Analysis of Food Waste Biorefineries at European Level. Bioresour. Technol. 2018, 259, 244-252.

(7) Caldeira, C.; Vlysidis, A.; Fiore, G.; De Laurentiis, V.; Vignali, G.; Sala, S. Sustainability of Food Waste Biorefinery: A Review on Valorisation Pathways, Techno-Economic Constraints, and Environmental Assessment. Bioresour. Technol. 2020, 312, 123575.

(8) Arancon, R. A. D.; Lin, C. S. K.; Chan, K. M.; Kwan, T. H.; Luque, R. Advances on Waste Valorization: New Horizons for a More Sustainable Society. Energy Sci. Eng. 2013, 1, 53-71.

(9) Møller, H.; Hanssen, O. J.; Gustavsson, J.; Östergren, K.; Stenmarck, A..; Dekhtyar, P. Report on Review of (Food) Waste Reporting Methodology and Practice; Ostfold Research: 2014.

(10) Scholz, K.; Eriksson, M.; Strid, I. Carbon Footprint of Supermarket Food Waste. Resour., Conserv. Recycl. 2015, 94, 56-65.

(11) Tuck, C. O.; Pérez, E.; Horváth, I. T.; Sheldon, R. A.; Poliakoff, M. Valorization of Biomass: Deriving More Value from Waste. Science 2012, 338, 695.

(12) Lin, C. S. K.; Pfaltzgraff, L. A.; Herrero-Davila, L.; Mubofu, E. B.; Abderrahim, S.; Clark, J. H.; Koutinas, A. A.; Kopsahelis, N.; Stamatelatou, K.; Dickson, F.; Thankappan, S.; Mohamed, Z.; Brocklesby, R.; Luque, R. Food Waste as a Valuable Resource for the Production of Chemicals, Materials and Fuels. Current Situation and Global Perspective. Energy Environ. Sci. 2013, 6, 426-464.

(13) Mirabella, N.; Castellani, V.; Sala, S. Current Options for the Valorization of Food Manufacturing Waste: A Review. J. Cleaner Prod. 2014, 65, 28-41.

(14) Maina, S.; Kachrimanidou, V.; Koutinas, A. A Roadmap towards a Circular and Sustainable Bioeconomy through Waste Valorization. Curr. Opin. Green Sustainable Chem. 2017, 8, 18-23.

(15) Fritsch, C.; Staebler, A.; Happel, A.; Márquez, M. A. C.; AguilóAguayo, I.; Abadias, M.; Gallur, M.; Cigognini, I. M.; Montanari, A.; López, M. J.; Suárez-Estrella, F.; Brunton, N.; Luengo, E.; Sisti, L.; Ferri, M.; Belotti, G. Processing, Valorization and Application of Bio-Waste Derived Compounds from Potato, Tomato, Olive and Cereals: A Review. Sustainability 2017, 9, 1492.

(16) Serna-Loaiza, S.; Miltner, A.; Miltner, M.; Friedl, A. A Review on the Feedstocks for the Sustainable Production of Bioactive Compounds in Biorefineries. Sustainability 2019, 11, 6765.

(17) Pleissner, D.; Qi, Q.; Gao, C.; Rivero, C. P.; Webb, C.; Lin, C. S. K.; Venus, J. Valorization of Organic Residues for the Production of Added Value Chemicals: A Contribution to the Bio-Based Economy. Biochem. Eng. J. 2016, 116, 3-16.

(18) Xiong, X.; Yu, I. K. M.; Tsang, D. C. W.; Bolan, N. S.; Sik Ok, Y.; Igalavithana, A. D.; Kirkham, M. B.; Kim, K. H.; Vikrant, K. ValueAdded Chemicals from Food Supply Chain Wastes: State-of-the-Art Review and Future Prospects. Chem. Eng. J. 2019, 375, 121983.

(19) Imbert, E. Food Waste Valorization Options: Opportunities from the Bioeconomy. Open Agric. 2017, 2, 195-204.

(20) Demichelis, F.; Fiore, S.; Pleissner, D.; Venus, J. Technical and Economic Assessment of Food Waste Valorization through a Biorefinery Chain. Renewable Sustainable Energy Rev. 2018, 94, 38-48.

(21) San Martin, D.; Ramos, S.; Zufía, J. Valorisation of Food Waste to Produce New Raw Materials for Animal Feed. Food Chem. 2016, 198, $68-74$.

(22) Dimou, C.; Vlysidis, A.; Kopsahelis, N.; Papanikolaou, S.; Koutinas, A. A.; Kookos, I. K. Techno-Economic Evaluation of Wine Lees Refining for the Production of Value-Added Products. Biochem. Eng. J. 2016, 116, 157-165.

(23) Ghayur, A.; Verheyen, T. V.; Meuleman, E. Techno-Economic Analysis of a Succinic Acid Biorefinery Coproducing Acetic Acid and Dimethyl Ether. J. Cleaner Prod. 2019, 230, 1165-1175. 
(24) Lee, J. C.; Lee, B.; Ok, Y. S.; Lim, H. Preliminary TechnoEconomic Analysis of Biodiesel Production over Solid-Biochar. Bioresour. Technol. 2020, 306, 123086.

(25) Wang, H.; Tsang, C.-W.; To, M.-H.; Kaur, G.; Roelants, S. L. K W.; Stevens, C. V.; Soetaert, W.; Lin, C. S. K. Techno-Economic Evaluation of a Biorefinery Applying Food Waste for Sophorolipid Production - A Case Study for Hong Kong. Bioresour. Technol. 2020, 303, 122852.

(26) Tesfaye, T.; Johakimu, J. K.; Chavan, R. B.; Sithole, B.; Ramjugernath, D. Valorisation of Mango Seed via Extraction of Starch: Preliminary Techno-Economic Analysis. Clean Technol. Environ. Policy 2018, 20, 81-94.

(27) Karka, P.; Papadokonstantakis, S.; Kokossis, A. Cradle-to-Gate Assessment of Environmental Impacts for a Broad Set of Biomass-toProduct Process Chains. Int. J. Life Cycle Assess. 2017, 22, 1418-1440.

(28) Broeren, M. L. M.; Kuling, L.; Worrell, E.; Shen, L. Environmental Impact Assessment of Six Starch Plastics Focusing on Wastewater-Derived Starch and Additives. Resour., Conserv. Recycl. 2017, 127, 246-255.

(29) Salomone, R.; Saija, G.; Mondello, G.; Giannetto, A.; Fasulo, S.; Savastano, D. Environmental Impact of Food Waste Bioconversion by Insects: Application of Life Cycle Assessment to Process Using Hermetia Illucens. J. Cleaner Prod. 2017, 140, 890-905.

(30) Schmidt Rivera, X. C.; Espinoza Orias, N.; Azapagic, A. Life Cycle Environmental Impacts of Convenience Food: Comparison of Ready and Home-Made Meals. J. Cleaner Prod. 2014, 73, 294-309.

(31) Khoshnevisan, B.; Tsapekos, P.; Alvarado-Morales, M.; Rafiee, S.; Tabatabaei, M.; Angelidaki, I. Life Cycle Assessment of Different Strategies for Energy and Nutrient Recovery from Source Sorted Organic Fraction of Household Waste. J. Cleaner Prod. 2018, 180, 360374.

(32) Lam, C. M.; Yu, I. K. M.; Medel, F.; Tsang, D. C. W.; Hsu, S. C.; Poon, C. S. Life-Cycle Cost-Benefit Analysis on Sustainable Food Waste Management: The Case of Hong Kong International Airport. J. Cleaner Prod. 2018, 187, 751-762.

(33) Negro, V.; Ruggeri, B.; Fino, D.; Tonini, D. Life Cycle Assessment of Orange Peel Waste Management. Resour., Conserv. Recycl. 2017, 127, 148-158.

(34) De Menna, F.; Davis, J.; Bowman, M.; Brenes Peralta, L.; Bygrave, K.; Garcia Herrero, L.; Luyckx, K.; McManus, W.; Vittuari, M.; van Zanten, H.; Ostergren, K. LCA \& LCC of Food Waste Case Studies : Assessment of Food Side Flow Prevention and Valorisation Routes in Selected Supply Chains; Refresh: 2019, 10.18174/478622.

(35) Sala, S.; Ciuffo, B.; Nijkamp, P. A Systemic Framework for Sustainability Assessment. Ecol. Econ. 2015, 119, 314-325.

(36) Taelman, S.; Sanjuan-Delmás, D.; Tonini, D.; Dewulf, J. An Operational Framework for Sustainability Assessment Including Local to Global Impacts: Focus on Waste Management Systems. Resour., Conserv. Recycl. 2020, 162, 104964.

(37) De Laurentiis, V.; Corrado, S.; Sala, S. Quantifying Household Waste of Fresh Fruit and Vegetables in the EU. Waste Manage. 2018, 77, 238-251.

(38) European Food Safety Authority Food Consumption Database; European Food Safety Authority: 2021. https://www.efsa.europa.eu/ en/food-consumption/comprehensive-database (accessed Jul 23, 2020).

(39) United Nations Environment Programme Food Waste Index Report 2021; 2021.

(40) Martinez-Sanchez, V.; Kromann, M. A.; Astrup, T. F. Life Cycle Costing of Waste Management Systems: Overview, Calculation Principles and Case Studies. Waste Manage. 2015, 36, 343-355.

(41) ISO Environmental Management-Life Cycle AssessmentRequirements and Guidelines (ISO 14044:2006), 1st ed., 2006.

(42) ISO. Environmental Management-Life Cycle AssessmentRequirements and Guidelines (ISO 14040:2006), 2nd ed., 2006.

(43) Weidema, B. P. Market Information in Life Cycle Assessment; Miljøprojekt: 2003.
(44) Weidema, B. P.; Ekvall, T.; Heijungs, R. Guidelines for Application of Deepened and Broadened LCA; Deliverable D18 of work package 5: 2009, 037075, 49.

(45) Tonini, D.; Hamelin, L.; Astrup, T. F. Environmental Implications of the Use of Agro-Industrial Residues for Biorefineries: Application of a Deterministic Model for Indirect Land-Use Changes. GCB Bioenergy 2016, 8, 690-706.

(46) Schmidt, J. H. User-Manual for the 2.-0 LCA ILUC Model; Aalborg: 2015.

(47) Wernet, G.; Bauer, C.; Steubing, B.; Reinhard, J.; Moreno-Ruiz, E.; Weidema, B. The Ecoinvent Database Version 3 (Part I): Overview and Methodology. Int. J. Life Cycle Assess. 2016, 21, 1218-1230.

(48) De Bruyn, S.; Bijleveld, M.; de Graaff, L.; Schep, E.; Schroten, A.; Vergeer, R.; Ahdour, S. Environmental Prices Handbook EU28 Version; CE Delft: 2018, 175 .

(49) Friedrich, R.; Quinet, E. External Costs of Transport in Europe. In A handbook of Transport Economics; Edward Elgar Publishing: 2011; 369-395, DOI: 10.4337/9780857930873.00024.

(50) Martinez-Sanchez, V.; Tonini, D.; Møller, F.; Astrup, T. F. LifeCycle Costing of Food Waste Management in Denmark: Importance of Indirect Effects. Environ. Sci. Technol. 2016, 50, 4513-4523.

(51) Christensen, T. H.; Gentil, E.; Boldrin, A.; Larsen, A. W.; Weidema, B. P.; Hauschild, M. C Balance, Carbon Dioxide Emissions and Global Warming Potentials in LCA-Modelling of Waste Management Systems. Waste Manage. Res. 2009, 27, 707-715.

(52) Clavreul, J.; Baumeister, H.; Christensen, T. H.; Damgaard, A. An Environmental Assessment System for Environmental Technologies. Environ. Modell. Software 2014, 60, 18-30.

(53) Teigiserova, D. A.; Hamelin, L.; Thomsen, M. Towards Transparent Valorization of Food Surplus, Waste and Loss: Clarifying Definitions, Food Waste Hierarchy, and Role in the Circular Economy. Sci. Total Environ. 2020, 706, 136033.

(54) Alexander, C.; Smaje, C. Surplus Retail Food Redistribution: An Analysis of a Third Sector Model. Resour., Conserv. Recycl. 2008, 52, 1290-1298.

(55) European Commission Commission Notice - Guidelines for the feed use of food no longer intended for human consumption; European Commision: 2018. C/2018/2035 https://eur-lex.europa.eu/legalcontent/EN/ALL/?uri=CELEX\%3A52018XC0416\%2801\%29.

(56) Coffee Based Coffee Recycle Service (CRS) - Coffee Based; Coffee Based: 2021. https://www.coffeebased.nl/en/coffee-recycle-service/ (accessed Sep 11, 2021).

(57) The Guardian Dutch companies set up giant bread bins to help cities tackle rat scourge | Guardian sustainable business; The Guardian: 2021. https://www.theguardian.com/sustainable-business/2017/jun/27/ dutch-companies-bread-bins-biogas-fertiliser-amsterdam-haguerotterdam (accessed Sep 11, 2021).

(58) Ekvall, T.; Weidema, B. P. System Boundaries and Input Data in Consequential Life Cycle Inventory Analysis. Int. J. Life Cycle Assess. 2004, 9, 161-171.

(59) Gentil, E. C.; Gallo, D.; Christensen, T. H. Environmental Evaluation of Municipal Waste Prevention. Waste Manage. 2011, 31, 2371-2379.

(60) Keramidas, K.; Tchung-Ming, S.; Siaz-Vazquez, A. R.; Weitzel, M.; Vandyck, T.; Despres, J.; Schmitz, A.; Rey Los Santos, L.; Wojtowicz, K.; Schade, B.; Saveyn, B.; Soria-Ramirez, A. Global Energy and Climate Outlook 2018: Sectoral Mitigation Options towards a LowEmissions Economy - Global Context to the EU Strategy for Long-Term Greenhouse Gas Emissions Reduction; Publication Office of the European Union: 2018, DOI: 10.2760/67475.

(61) Bisinella, V.; Conradsen, K.; Christensen, T. H.; Astrup, T. F. A Global Approach for Sparse Representation of Uncertainty in Life Cycle Assessments of Waste Management Systems. Int. J. Life Cycle Assess. 2016, 21, 378-394.

(62) Ciroth, A.; Muller, S.; Weidema, B. P. Refining the pedigree matrix approach in ecoinvent; GreenDelta: 2012. https://lca-net.com/ publications/show/refining-pedigree-matrix-approach-ecoinvent/.

(63) Laner, D.; Feketitsch, J.; Rechberger, H.; Fellner, J. A Novel Approach to Characterize Data Uncertainty in Material Flow Analysis 
and Its Application to Plastics Flows in Austria. J. Ind. Ecol. 2016, 20, 1050-1063.

(64) Muller, S.; Lesage, P.; Ciroth, A.; Mutel, C.; Weidema, B. P.; Samson, R. The Application of the Pedigree Approach to the Distributions Foreseen in Ecoinvent V3. Int. J. Life Cycle Assess. 2016, 21, 1327-1337.

(65) Weidema, B. P.; Bauer, C.; Hischier, R.; Mutel, C.; Nemecek, T. Overview and Methodology: Data Quality Guideline for the Ecoinvent Database Version 3; MIT Press: 2013.

(66) Ögmundarson, Ó.; Sukumara, S.; Laurent, A.; Fantke, P. Environmental Hotspots of Lactic Acid Production Systems. GCB Bioenergy 2020, 12, 19-38.

(67) Albizzati, P. F.; Tonini, D.; Astrup, T. F. High-Value Products from Food Waste: An Environmental and Socio-Economic Assessment. Sci. Total Environ. 2021, 755, 142466.

(68) Andreasi Bassi, S.; Boldrin, A.; Frenna, G.; Astrup, T. F. An Environmental and Economic Assessment of Bioplastic from Urban Biowaste. The Example of Polyhydroxyalkanoate. Bioresour. Technol. 2021, 327, 124813.

(69) Lam, K. F.; Leung, C. C. J.; Lei, H. M.; Lin, C. S. K. Economic Feasibility of a Pilot-Scale Fermentative Succinic Acid Production from Bakery Wastes. Food Bioprod. Process. 2014, 92, 282-290.

(70) Kwan, T. H.; Hu, Y.; Lin, C. S. K. Techno-Economic Analysis of a Food Waste Valorisation Process for Lactic Acid, Lactide and Poly(Lactic Acid) Production. J. Cleaner Prod. 2018, 181, 72-87.

(71) Ögmundarson, Ó.; Herrgård, M. J.; Forster, J.; Hauschild, M. Z.; Fantke, P. Addressing Environmental Sustainability of Biochemicals. Nat. Sustainability 2020, 3, 167-174.

(72) Sala, S.; Reale, F.; Cristóbal-García, J.; Marelli, L.; Rana, P. Life Cycle Assessment for the Impact Assessment of Policies. Life Thinking and Assessment in the European Policies and for Evaluating Policy Options; Joint Research Centre: 2016, DOI: 10.2788/318544.

(73) Zampori, L.; Pant, R. Suggestions for Updating the Product Environmental Footprint (PEF) Method, EUR 29682 EN, Publications Office of the European Union; Luxembourg: 2019, DOI: 10.2760/ 424613.

(74) Cristóbal, J.; Castellani, V.; Manfredi, S.; Sala, S. Prioritizing and Optimizing Sustainable Measures for Food Waste Prevention and Management. Waste Manage. 2018, 72, 3-16. 